\title{
Author Correction: Control of tumor-associated macrophages and Tcells in glioblastoma via AHR and CD39
}

Maisa C. Takenaka, Galina Gabriely, Veit Rothhammer, Ivan D. Mascanfroni, Michael A. Wheeler, Chun-Cheih Chao, Cristina Gutiérrez-Vázquez, Jessica Kenison, Emily C. Tjon, Andreia Barroso, Tyler Vandeventer, Kalil Alves de Lima, Sonja Rothweiler, Lior Mayo, Soufiene Ghannam, Stephanie Zandee, Luke Healy ID, David Sherr, Mauricio F. Farez, Alexandre Prat (D), Jack Antel, David A. Reardon, Hailei Zhang, Simon C. Robson, Gad Getz (D), Howard L. Weiner and Francisco J. Quintana (D)

Correction to: Nature Neuroscience https://doi.org/10.1038/s41593-019-0370-y, published online 8 April 2019.

In the version of this article initially published, author Alexandre Prat's surname was misspelled. The error has been corrected in the HTML and PDF versions of the article.

Published online: 13 June 2019

https://doi.org/10.1038/s41593-019-0446-8

\section{Author Correction: Loss of function of NCOR1 and NCOR2 impairs memory through a novel GABAergic hypothalamus-CA3 projection}

Wenjun Zhou, Yanlin He (D), Atteeq U. Rehman, Yan Kong, Sungguan Hong, Guolian Ding, Hari Krishna Yalamanchili, Ying-Wooi Wan, Basil Paul, Chuhan Wang, Yingyun Gong, Wenxian Zhou, Hao Liu, John Dean, Emmanuel Scalais, Mary O'Driscoll, Jenny E. V. Morton, DDD study, Xinguo Hou, Qi Wu, Qingchun Tong (D), Zhandong Liu, Pengfei Liu (D), Yong Xu(D) and Zheng Sun (D)

Correction to: Nature Neuroscience https://doi.org/10.1038/s41593-018-0311-1, published online 21 January 2019.

In the version of this article initially published, the Acknowledgements erroneously included a grant number that did not directly support the work in the article. The last sentence of the Acknowledgments should have read, “The authors' laboratories were supported by National Natural Science Foundation of China grants 31671222 and 31571556 (G.D.), a Taishan Scholarship (X.H.), the American Diabetes Association (ADA1-17-PDF-138) (Y.H.), the US Department of Agriculture (USDA) Cris6250-51000-059-04S (Y.X.), National Institutes of Health grants R01DK101379, R01DK117281, P01DK113954, R01DK115761 (Y.X.), the American Heart Association grant AHA30970064 (Z.S.), and grants R21CA215591 and R01ES027544 (Z.S.)." The error has been corrected in the HTML and PDF versions of the article. 